Cultura 


\section{Os impedimentos da memória} JEANNE MARIE GAGNEBIN ${ }^{I}$

\section{Introdução}

$\mathrm{D}$ ESDE A "Advertência" de seu livro mestre sobre $A$ memória, a história, o esquecimento, Ricoeur (2007, p.17) nos surpreende afirmando que essa nova pesquisa se deve a uma "lacuna" em sua obra, a saber, a falta de uma reflexão mais aprofundada sobre a memória e, mais ainda, sobre o esquecimento. O leitor que leu as belas análises de Ricoeur sobre Proust, Santo Agostinho ou mesmo Nietzsche fica surpreso, mesmo se a honestidade e a modéstia do autor sejam bem conhecidas. A essa "preocupação privada", acrescenta Ricoeur, se une uma "preocupação pública" que orienta toda a escrita desse grande livro e talvez explique essa nova obra:

Preocupação pública: perturba-me o inquietante espetáculo que apresentam o excesso de memória aqui, o excesso de esquecimento acolá, sem falar da influência das comemorações e dos erros de memória - e de esquecimento. A ideia de uma política da justa memória é, sob esse aspecto, um de meus temas cívicos confessos. (Ricoeur, 2010, tradução br. 2007, p.17)

Assim, podemos estabelecer uma primeira hipótese: esse novo trabalho de Paul Ricoeur (2000/2007), após os três volumes de Tempo e narrativa ou a reflexão sobre a identidade de O si-mesmo como outro (Ricoeur, 1990, trad. br. 2014), não se deve apenas a uma preocupação de honestidade intelectual, mesmo da exaustividade que essas obras também testemunham. Esse novo livro faz parte de uma preocupação cada vez mais política, no sentido de uma ética da cidadania e das instituições, do pensamento ricoeuriano. Certamente Ricoeur sempre teve essa preocupação com a política e seus paradoxos. Mas, a partir do final da década de 1980, essa preocupação acentua-se, como se a reflexão hermenêutica e linguística, realizada com paciência e obstinação, pudesse finalmente levar a uma filosofia prática, passar Do texto à ação, segundo o título de seu segundo volume de ensaios hermenêuticos (Ricoeur, 1986). ${ }^{1}$ Assim, os dois volumes intitulados $O$ justo (Ricoeur, 2008a/b), que traçam uma verdadeira filosofia do direito. Nesse itinerário, A memória, a história, o esquecimento marca a virada, porque esse livro não apenas dialoga com a historiografia contemporânea, notadamente francesa, como fizeram o primeiro e o último volumes de Tempo e narrativa, mas porque se confronta diretamente com a "bulimia comemorativa" que tentam pensar os grandes volumes organizados por Pierre Nora em torno dos Lieux de mémoire, e à qual para o desgosto de seu autor e organizador eles parecem ter contribuído. ${ }^{2}$

No entanto, e essa será minha segunda hipótese, mesmo que Ricoeur e Nora sejam ambos de acordo, como diz François Dosse (2004, p.256-70) em 
um belo artigo que corrige a recepção frequentemente distorcida, até odiosa, de A memória, a história, o esquecimento em revistas e jornais parisienses, se ambos defenderem "com a mesma firmeza o dever, a dívida das gerações atuais em relação ao passado", na esteira desse "rito fúnebre" que é a escrita da história segundo Michel de Certeau, a obra de Ricoeur é um hino ao que ele chama de uma memória viva, não apenas fiel mas até mesmo «feliz". ${ }^{3}$ Nesse sentido, Ricoeur defende a precedência da memória sobre a operação histórica:

A injunção a se lembrar corre o risco de ser entendida como um convite dirigido à memória para que provoque um curto-circuito no trabalho da história. Por meu lado, estou tanto mais atento a esse perigo pelo fato de meu livro ser uma apologia da memória como matriz de história, na medida em que ela continua sendo a guardiã da problemática da relação representativa do presente com o passado. (Ricoeur, 2007, p.100)

A questão de A memória, a história, o esquecimento pode, portanto, ser descrita como sendo ao mesmo tempo uma tomada de posição firme para com uma "política da justa memória" (Ricoeur, 2007) e uma reabilitação, de origem fenomenológica, da primazia da memória contra sua redução a um sentimento subjetivo, até privado de interesse epistemológico. Essa primazia ontológica da memória explicaria talvez a curiosa falta de um "Prelúdio" na construção da obra. Uma vez que a segunda e a terceira partes (respectivamente "História/ Epistemologia" e "A condição Histórica") são precedidas por prelúdios que formulam uma dúvida, uma interrogação que problematizam as reflexões a serem seguidas; a primeira parte, "Da memória e da reminiscência", começa logo após uma breve "nota de orientação geral", nota também presente para a segunda e a terceira partes. Parece, portanto, que a memória goza de um status privilegiado: mesmo que ela não configure nenhuma origem última, visto que a filosofia deve fazer o luto da possibilidade dessa figura, não obstante ela é a primeira porque não dedutível, ela nasce com a linguagem humana e até a precede na história singular e não dita do corpo de cada um. Já na famosa conclusão de La philosophie de la volonté intitulada "O símbolo dá o que pensar", Ricoeur (1960, p.324) afirmou em conjunto a impossibilidade de uma filosofia "sem pressuposto" e a necessidade, para a filosofia, ancorada na plenitude da linguagem, de "se recordar para começar". ${ }^{4}$ Desde Platão, a filosofia nasce com a linguagem, e o logos é como a articulação de uma anamnese primeira cujo "objeto" é inatingível - pelo menos pela filosofia que, no entanto, gostaria de poder dar-lhe um nome.

\section{Pierre Nora: entre memória e história}

Essa precedência ontológica da memória sobre a história pode nos iluminar sobre as diferenças que existem, a despeito de todos os pontos comuns, entre o diagnóstico de Nora e a tentativa de Ricoeur. Em seu texto teórico introdutório ao projeto dos Lieux de mémoire, texto intitulado "Entre mémoire et histoire", Pierre Nora descreve com sagacidade e, com frequente humor, nossa excessiva preocupação contemporânea a respeito da memória. Colóquios, 
estudos, projetos de pesquisa, os números de periódicos, todos eles são incontáveis sobre esse assunto. Certamente a preocupação com a memória do passado, especialmente dos mortos do passado, já guia os kleos grego e toda a poesia homérica, mas essa preocupação assume hoje características específicas: é porque não estamos mais inseridos em uma tradição de memória viva, oral, comunitária e coletiva - como tentava descrever Maurice Halbwachs - que precisamos lutar contra essa caducidade das obras e das existências humanas, que criamos tantas estratégias de conservação, arquivos, gravações, vídeos, centros de memória. Nora propõe, portanto, esboçar nos sete volumes de Lieux de mémoire uma história verdadeira das relações complementares entre memória e história, e de suas várias manifestações, dos memoriais aos mortos, aos grandes dicionários e aos múltiplos centenários (e bicentenários).

Para fazer isso, ele parte de uma definição intuitiva daquilo que geralmente chamamos "memória" e daquilo que entendemos como "história", no sentido de uma disciplina científica. Ao fazê-lo, Nora retoma implicitamente uma hipótese-chave da sociologia alemã do final do século XIX (Ferdinand Tönnies e Georg Simmel em particular), que estabeleceu como uma característica específica da nossa contemporaneidade desde, grosso modo, a Primeira Guerra Mundial - mas sendo sua fonte muito mais antiga no desenvolvimento do capitalismo industrial - isto é, o fim de uma relação de continuidade imediata entre o presente e o passado. Isso é também o que Walter Benjamin descreve como o fim da experiência, no pleno sentido do termo alemão Erfahrung, experiência compartilhada e transmitida de geração em geração. $\mathrm{O}$ desenvolvimento da técnica, um dos principais temas da sociologia e da filosofia após as bombas da Primeira Guerra, e a aceleração da produção industrial cava entre gerações sucessivas (e às vezes dentro da mesma geração) um abismo de experiência e vida que torna a transmissão das histórias e o significado dessas histórias, do sentido da vida, profundamente problemático, até impossível. Tönnies usa a oposição entre comunidade (Gemeinschaft) e sociedade (Gesellschaft), ou seja, a passagem de um organização social restrita, orgânica e até familiar, ligada à agricultura e ao artesanato, a uma organização social muito mais ampla, e até global, governada pelas duras leis de um capitalismo competitivo e da produção industrial, para retratar essa transformação. É também a transição do convívio das aldeias rurais para o anonimato das grandes cidades industriais, das megacidades de hoje. Nora aborda esse tema quando sinaliza a ruptura operada pelo fim do campesinato na França.

Não me atreveria a discutir aqui nem os méritos dessas descrições nem a veracidade delas. O que é claro é que elas geralmente são acompanhadas por uma forte idealização do passado, de uma nostalgia pela perda da comunidade (a qual não podemos realmente dizer se foi tão harmoniosa) e de uma acusação, muitas vezes justificada, em relação ao nosso presente competitivo, globalizado e anônimo, reclamação que vai contudo acompanhada com um certo entusiasmo pela invenção ilimitada de novas mercadorias e a aceleração de sua produção. $\mathrm{O}$ 
que eu gostaria de salientar é que Nora assume implicitamente esse quadro teórico quando fala de "L'arrachement de ce qui restait encore de vécu dans la chaleur de la tradition, dans le mutisme de la coutume, dans la répétition de l'ancestral sous la poussée d'un sentiment historique de fond", para concluir com uma bela fórmula irônica: "On ne parle tant de mémoire que parce qu'il n'y en a plus". $\mathrm{A}$ diferença aumenta entre uma "história-memória”, ou seja, para Nora, uma "tradição histórica" que "s'est développée comme l'exercice réglé de la mémoire et son approfondissement spontane" e uma "história crítica", que não apenas denuncia os mitos, mas "se met en devoir de traquer en elle ce qui n'est pas elle, se découvrant victime de la mémoire et faisant un effort pour s'en délivrer". " Enquanto "P histoire est devenue une science sociale", "la mémoire [est] un phénomène purement privé", 8 conclui Nora talvez de maneira abrupta, passando de um "monde où l'on avait des ancêtres à un monde du rapport contingent à ce qui nous a faits".

O grande mérito das reflexões de Pierre Nora consiste nesse questionamento da memória, em sua historicização: funções, exercícios e valores da memória mudando profundamente de acordo com o contexto histórico de cada cultura, oral ou escrita, camponesa, artesanal ou industrial, por exemplo. Essas mudanças são a prova de que a memória não é uma faculdade antropológica imutável, mas a expressão de uma relação com a temporalidade humana, um relacionamento em si impregnado de historicidades singulares. Como historiador da memória, Nora chama a atenção em particular para o entusiasmo contemporâneo pelos projetos de preservação, conservação, de salvaguarda que, segundo ele, nascem menos de uma vontade natural de lembrar e mais da consciência aguda - mesmo que pouco explícita - da fragilidade e da caducidade das tradições passadas, mais geralmente de todas as obras humanas, especialmente das nossas. Portanto, nosso desejo de conservação, nosso arquivismo ilimitado, seria mais o sinal da ansiedade com a aceleração dos processos de destruição e obsolescência, e não o resultado de uma deliberação cuidadosa sobre o valor - ou não - do que nós nos esforçamos para preservar. Essa tendência a uma conservação exaustiva é também a de uma historiografia acadêmica cuja erudição estéril Nietzsche já denunciou, na Segunda consideração intempestiva, a erudição estéril. A redução do gesto memorial a um gesto de preservação atesta certamente uma preocupação de respeito, até de piedade, mas tende a secar a força de vida desse ato, transformando a memória numa prática de embalsamamento.

Não se pode deixar de notar que o próprio Nora parece ser vítima de uma certa nostalgia, até mesmo de uma idealização da memória "verdadeira", com a que ele próprio havia contribuído a denunciar como um sinal de nossa contemporaneidade ansiosa, quando ele declara:

Sans doute est-il impossible de se passer du mot [du mot de "mémoire"]. Acceptons-le, mais avec la conscience claire de la différence entre la mémoire vraie, aujourd'hui réfugiée dans le geste et l'habitude, dans les métiers où se transmettent les savoirs du silence, dans les savoirs du corps, les mémoires 
d'imprégnation et les savoirs réflexes, et la mémoire transformée par son passage en histoire, qui en est presque le contraire: volontaire et délibérée, vécue comme un devoir et non plus spontanée; psychologique, individuelle et subjective, et non plus sociale, collective, englobante. ${ }^{10}$

Essas afirmações são ambíguas: por que opor a memória verdadeira à “ $m e ́-$ moire saisie par l' histoire", como Nora chama no segundo subtítulo de sua grande introdução geral, uma vez que tínhamos entendido que a memória é sempre uma figura histórica, não uma essência "verdadeira" e imutável? Talvez - e essa é minha suspeita - para melhor destacar as prerrogativas da disciplina histórica que prevalece e deve prevalecer hoje em nossa relação com o passado. A história, pois, essa disciplina científica, "voluntária e deliberada", é promovida a uma espécie de consciência crítica da nação - e seu porta-voz, o historiador, como garantidor da busca da verdade contra o caráter emocional e sempre subjetivo das reivindicações memoriais. Assim já aponta, no início deste projeto histórico dos "Lieux de mémoire", o alerta do historiador crítico contra a febre comemorativa e identitária a qual o Estado francês se vê forçado no final do século XX: desde a ênfase na memória da Shoah, cada um parece ter o direito de reivindicar a celebração de sua história, geralmente dolorosa, de sua identidade perante os órgãos oficiais da República Francesa. Daí a constatação irônica, mas também exasperada do historiador Nora no final desses sete volumes:

C'est la dynamique même de la commémoration qui s'est inversée, le modèle mémoriel l'a emporté sur le modèle historique, et, avec lui, un tout autre usage du passé, imprévisible, capricieux. Un passé qui a perdu son caractère organique, péremptoire et contraignant. Ce n'est pas ce qu'il nous impose qui compte mais ce que l'on y met. D'où le brouillage du message, quel qu'il soit. C'est le présent qui crée ses instruments de commémoration, qui court après les dates et les figures à commémorer, qui les ignore ou les multiplie, qui s'en donne d'arbitraires à l'intérieur du programme imposé (tel Valmy annexé à 1789) ou qui subit la date (par exemple 1994 pour l'affaire Dreyfus, la condamnation, pas la réhabilitation), mais pour en transformer la signification. L’histoire propose, mais le présent dispose, et ce qui se passe est régulièrement différent de ce que l'on voulait. ${ }^{11}$

Entendemos que essa "refabrication du passe""12 é suficiente para irritar Pierre Nora, representante de uma história científica “telle qu'elle s'est constituée en institutrice de la nation", ${ }^{13}$ como ele coloca belamente. É de fato uma crise dessa tradição, portanto uma crise da filiação à nação, sinalizada por essa efervescência comemorativa - e isso a favor de iniciativas de identidade assumidas "avec les moyens du bord, des plus sauvages aux plus scientifiques" 14 por muitos grupos, na maioria das vezes por aqueles que se sentiram sufocados ou justificadamente ignorados pelas autoridades nacionais. A passagem "de L historique au remémoratif et du remémoratif au commémoratif" 15 indica, assim, dois fenômenos relacionados, o rompimento da unidade "Nação" e a crescente distância entre um modelo crítico com pretensão científica de apreensão do passado, passado reco- 
nhecido como um bem comum de todos os cidadãos de uma mesma unidade nacional e uma pluralidade de memórias soterradas que reivindicam a sua volta à existência e à consciência, sem se preocupar em primeiro lugar com o caráter científico deste discurso. Donde um jorro de comemorações e de contracomemorações que indicam mais uma problemática do presente do que uma atenção ao passado. A história não é mais "une mémoire vérifiée" ${ }^{16}$ onde cada um podia encontrar seu lugar, mas se tornou uma narrativa dilacerada, conglomerado de narrativas parciais ou mesmo partidariais, muitas vezes militantes.

\section{Paul Ricoeur e a memória viva}

Paul Ricoeur (2007, p.421) observou a "amargura" do historiador. No entanto, parece-me que todo o livro de Ricoeur defende outra concepção de memória, muito diferente daquela que é denunciada por Nora (1997) como um aglomerado de memórias diversas ("memória operária, occitana, feminina" por exemplo) que têm em comum a reivindicação de uma identidade até agora desprezada ou silenciada. Ricoeur evita a armadilha da questão identitária (não nos esqueçamos de que $A$ memória, a história, o esquecimento é escrito após $O$ si-mesmo como outro!) para aprofundar uma concepção de memória ligada à vida, como Bergson o queria, abundantemente citada nesse livro (em oposição a uma certa distância em relação a Heidegger).

Ricoeur, portanto, insiste que não podemos prescindir da memória para poder estabelecer uma relação com o passado. Retomando a citação de Aristóteles, "A memória é do passado", ${ }^{17}$ ele deixa temporariamente de lado o problema epistemológico da fidelidade ou da verdade da memória para enfatizar seu status transcendental. Sem memória, o passado não existiria para nós, estaríamos tão presos a um presente que seria constantemente adicionado a outro presente:

Para falar sem rodeios, não temos nada melhor que a memória para significar que algo aconteceu, ocorreu, se passou antes que declarássemos nos lembrar dela. (Ricoeur, 2007, p.40)

Portanto, é esse statuto transcendental que nos obriga a refletir, por assim dizer, a montante, antes da questão da exatidão ou não de nossas lembranças, a refletir sobre esse vínculo com o passado que nos constitui e que só percebemos através da memória. A distinção bergsoniana entre memória-hábito e memória-lembrança sublinha essa temporalidade viva, pela oposição entre a repetição do hábito - daquilo que aprendemos no passado e que estamos reativando - e o lembrar de eventos únicos que às vezes surgem sem o nosso esforço consciente $\mathrm{e}$ manifestam a imprevisibilidade e a espontaneidade da vida. À memória-repetição se opõe essa memória que traz de volta o passado esquecido, ou nunca realmente percebido, o que Proust chamava de pequenas "ressurreições da memória" porque esse passado estava morto e que subitamente salta para o palco do presente, transformando-o.

A leitura atenta de Reinhart Koselleck (1979), ao termo de Tempo e narrativa, perseguiu um objetivo análogo: a saber, que o "espaço da experiência" 
que extraímos do passado e o "horizonte de espera" que podemos projetar sobre o futuro são as condições de possibilidade de um presente verdadeiramente vivo, portanto enraizado em uma temporalidade reconhecida e assumida. Ricoeur desloca, portanto, a questão epistemológica da exatidão, ou não, das lembranças, questão ligada a todos os avatares da imagem e da imaginação, ${ }^{18}$ para se debruçar sobre uma análise da memória como condição de possibilidade da vida humana, essa existência temporal que conhece seu passado e seu futuro, que sabe de sua finitude, mas também de sua inventividade (o Dasein heideggeriano sendo retomado com uma forte conotação positiva da afirmação de vida).

Para Ricoeur, o problema se transfere da "representação" do passado, em alemão Vorstellung, imagem mental que o historiador se esforça para evocar de maneira precisa e verificável, ao da "representância", no alemão Vetretung, um ato de lembrar que quer representar (vertreten), no sentido político e ético da palavra, como um deputado representa seus eleitores: representância dos mortos do passado, em particular de suas lutas e de suas esperanças. Como o enfatizam Olivier Abel e Jérôme Porée (2007, p.72), é "a dialética de não ser mais que dá a medida do desaparecimento do passado e do ter sido que atesta sua presença ausente", o que dá a representância sua densidade ontológica. Não se trata apenas de conhecer o melhor possível o passado, como gostaria o historiador, mas de retomar seus gestos inacabados e suas aspirações, portanto de lembrar de seus sofrimentos.

Nesse sentido, a representância, próxima ao Eingedenken (que eu traduziria por rememoração, algo muito diferente da noção de comemoração) de Walter Benjamin, proclama mais a necessidade de não esquecer, o que não é sinônimo de "dever da memória", rapidamente transformado e alienado em comemoração oficial. $\mathrm{Na}$ fonte dessa relação memorial, certamente há uma injunção teológica que encarnam as palavras de Jesus aos seus discípulos, instituindo a Ceia antes de ser entregue ao tribunal e à morte: "Façam isso em minha memória" ${ }^{19}$ Relação que, no entanto, pode ser de ordem ética e política, sem pressupor uma fidelidade religiosa determinada. Podemos observar que Walter Benjamin também assumiu à sua maneira um legado teológico quando ele observou, respondendo às objeções de Max Horkheimer ao seu projeto historiográfico:

O corretivo desta linha de pensamento [as de Horkheimer sobre a caducidade do passado] pode ser encontrado na consideração de que a história não é apenas uma ciência, mais igualmente uma forma de rememoração. [...] Esta pode transformar o inacabado (a felicidade) em algo acabado e o acabado (sofrimento) em algo inacabado. Isto é teologia; na rememoração, porém, fazemos uma experiência que nos proíbe de conceber a história como fundamentalmente ateológica, embora tampouco nos seja permitido tentar escrevê-la com conceitos imediatamente teológicos. (Benjamin, 2009, p.513) 


\section{Dimensão ética e política da memória}

Essa relação de representância explica a veemência com a qual Ricoeur insiste na relação entre memória do passado e exigência ética, opondo à "tirania da memória" e à febre comemorativa, justamente denunciadas por Pierre Nora, uma necessidade de pensar o trabalho de memória "sob a égide da idéia de justiça" (Ricoeur, 2007, p.104). Ora, a justiça só pode ser pensada no presente, a saber: como se lembrar fazendo justiça a esse passado (vergangen), é claro, mas contudo ainda e sempre inscrito no presente, um passado (gewesen) presente? Em que minha atividade presente faz justiça ao passado? Essa relação entre o passado, em particular entre os sofrimentos do passado e o presente, carrega a atividade memorial com o peso de uma tarefa que proíbe defini-la como uma figura ideal de objetividade, aquilo que a ciência histórica visa. Esse lado emocional (no vocabulário de Pierre Nora) da memória não se esgota em um subjetivismo reivindicativo, mas sublinha o vínculo de vida que une o presente ao passado. A memória, como força vital, nos permitiria prestar contas da dívida que temos com o passado - mas também de não permanecer nela eternamente presos, vítimas dessa tendência mortífera que Nietzsche denuncia na Segunda Dissertação da Genealogia da moral quando ele analisa a relação entre dívida (Schuld) e culpa (Schuld).

Quando ele introduz conjuntamente as noções de "representância" e "dívida" no terceiro volume de Tempo e narrativa, Ricoeur (2010, p.266) cita Michel de Certeau, em particular sua releitura do texto de Freud, Moisés e o monoteísmo, e a "dupla relação de contestação e pertencimento" que caracteriza o Moisés freudiano. A partir de agora, Certeau e Freud acompanham a reflexão ricoeuriana sobre o "enigma da preteridade" (Ricoeur, 2010, p.267), este passado que interpela os homens do presente e lhes ordena não apenas a não esquecê-lo, mas também a "restituir aos homens do passado - aos mortos - o que lhes é devido" (Ricoeur, 2010, p.268). A tarefa da memória, portanto, não é apenas de lembrar, mas de lembrar respondendo a uma interpelação, um tema que encontramos em Arendt e em Benjamin.

Todas as estratégias de impedimento da memória, "Memória impedida, memória manipulada, memória comandada de modo abusivo", conforme listado no subtítulo do capítulo II de A memória, a história, o esquecimento, (Ricoeur, 2007, p.82) portanto, não visam simplesmente uma falsificação da lembrança, mas muito mais: elas tendem a impedir a escuta dessa interpelação e a resposta que lhe poderia ser dada no presente, dentro do presente e para o presente. É por isso que Ricoeur vai se confrontar com as dimensões propriamente políticas da memória e do esquecimento. A necessidade de um uma reflexão mais aprofundada sobre o tema do esquecimento surge da afirmação de renovação que as "ressurreições da memória" tornam possível, portanto, de uma distinção entre uma memória concebida como um vasto armazém cheio de objetos de todos os tipos, de acordo com as descrições clássicas de Santo Agostinho, ${ }^{20}$ e essa memó- 
ria viva e espontânea que se lembra não se sabe donde. Assim Ricoeur distingue, nos passos de Proust e Freud, um esquecimento como o apagamento dos rastros e um "esquecimento de reserva", reserva de vida e de surpresa quando o sujeito, singular e também coletivo, concorda em não controlar de um punho de ferro, o de sua consciência, o processo da lembrança. Ousar apostar na "sobrevivência das imagens" 21 na alegria e na vergonha que essas imagens enterradas provocam em nós, é, segundo a lição de Freud retomada por Ricoeur, ousar apostar em uma nova vida no presente.

$\mathrm{O}$ esquecimento de reserva permite melhor entender o quanto todas as formas de esquecimento impostas - quer pelo superego do sujeito singular ou por uma política de "esquecimento comandado", pelas numerosas leis de anistia, ${ }^{22}$ embora possam de fato impedir a menção de lembrança e então a silenciar -, que essas várias táticas nunca consigam produzir apaziguamento (ou "reconciliação da nação", como dizem alguns governos), que deveria justificá-las. Impor o esquecimento é, paradoxalmente, impor uma forma única de memória, produzindo ao mesmo tempo uma "memória impedida" que não cessa de sempre voltar e solapar o difícil equilíbrio alcançado: a memória viva reivindica sua independência e contesta as disposições precárias da memória oficial. Em páginas preciosas e precisas sobre a figura política da anistia, Ricoeur insiste sobre o caráter temporário dessa decisão, às vezes necessário para alcançar a sobrevivência imediata da cidade (Atenas em 403 a.C. após a vitória dos democratas sobre os Trinta Tiranos) ou da nação (com o Edito de Nantes em 1598, que deve pôr um fim às guerras fratricidas da religião). A anistia é, portanto, um gesto de interrupção (Ricoeur, 2007, p.460), de cesura que deve permitir que um grupo permaneça um grupo, discordante, dividido certamente, mas, no entanto, capaz de continuar uma vida em comum. Mas a anistia não abole o conflito, também uma condição dessa vida em comum. Ela significa, portanto, uma trégua ao conflito, trégua talvez necessária, mas que não pode pretender constituir uma regra eterna. É por isso que "a proximidade mais que fonética, e até semântica, entre anistia e amnésia" (Ricoeur, 2007, p.460), ou seja, a confusão entre anistia e esquecimento, e até perdão, ${ }^{23}$ deve ser vigorosamente denunciada.

Como Jacques Derrida, Ricoeur se debruçou muito tempo sobre a política incorporada na África do Sul pela Comissão da "Verdade e Reconciliação", criada após sua saída da prisão por Nelson Mandela, que se tornou presidente. O objetivo dessa comissão não era conciliar os concidadãos defendendo o esquecimento dos crimes do apartheid, mas, pelo contrário, permitindo uma retomada de sua vida em comum, enquanto grupo - o que a palavra africana Ubuntu $u^{24}$ significa - sobre a base da narração pública e completa dos crimes cometidos. $\mathrm{O}$ deslize fatal da anistia para o esquecimento, à memória impedida, só pode ser combatido pela confissão e pelo relato dos crimes, uma retomada narrativa que explica o caráter de trégua temporal da instituição de anistia, necessário para pôr fim a uma luta sangrenta, uma trégua que não é sinônimo de esquecimento ou 
de silêncio no futuro. É isso que Ricoeur destaca em um artigo que cita a Comissão Sul-Africana:

Donc le lien de l'amnistie à l'aveu devient l'essentiel. Elle est individuelle et conditionnelle, à l'inverse des amnisties générales octroyées en Amérique latine sous la pression des militaires. Par l'aveu, elle est liée à la parole et à son juste pacte avec la vérité et non au silence du non-dire, comme dans la justice violente où s'efface la frontière entre amnistie et amnésie commandée. ${ }^{25}$

Ricoeur estabelece, portanto, uma distinção nítida entre uma política de anistia, como estratégia temporal de paz social para permitir que a nação se recomponha como tal, e um desejo implícito de impor uma amnésia política, de poder impor uma narrativa do passado que apaga definitivamente certos episódios como se eles simplesmente não tivessem acontecido e não deixassem nenhum rastro. Assim, ele destaca não apenas os riscos de qualquer prática de anistia, mas também suas prováveis consequências, ainda mais que geralmente são os vencedores que proclamam uma anistia, talvez geral, mas que na maioria das vezes os protege bem mais do que seus adversários. ${ }^{26}$ Assim, ele escrevia seis anos antes da publicação de $A$ memória, a história, o esquecimento:

À l'interdiction de toute action en justice, donc à l'interdiction de toute poursuite de criminels, s'ajoute l'interdiction d'époquer les faits eux-mêmes sous leur qualification criminelle. Il s'agit donc d'une véritable amnésie institutionnelle invitant à faire comme si l'épénement n'avait pas eu lieu. [...] Le prix à payer est lourd. Tous les méfaits de l'oubli sont contenus dans cette prétention incroyable à effacer les traces des discordes publiques. C'est en ce sens que l'amnistie est un contraire du pardon, lequel [...] requiert la mémoire. (Ricoeur, 1995, p.206) ${ }^{27}$

\section{O modelo freudiano}

"Fazer como se a situação não tivesse acontecido": esse gesto é a fonte das patologias da memória que Freud descreveu. Memória impedida pelas feridas traumáticas e/ou pelas resistências do recalque que só podem se transformar em memória viva e verdadeira pelo longo trabalho da fala e da narração. $\mathrm{Na}$ trilha aberta por Tempo e narrativa e de O si-memo como outro, Ricoeur insiste na mediação narrativa, não apenas para dizer o tempo, para contar sua história e, assim, ousar construir uma identidade pessoal como ipseidade, mas também, em A memória, a história, o esquecimento, para passar do esquecimento que não quer saber a uma palavra que busque a verdade. O paradigma freudiano é assumido tanto na parte da obra dedicada à memória, quanto naquela dedicada ao esquecimento (Ricoeur, 2007, p.83-93, 452-62).

O pequeno texto de Freud "Rememoração, repetição, perlaboração", ${ }^{28}$ abundantemente citado, data de 1914. Geralmente publicado nos volumes que tratam das reflexões de Freud sobre a "técnica" da cura psicanalítica, ele se propõe, de fato, a exortar tanto o analista quanto o analisando à paciência... e ao trabalho (durcharbeiten). A evocação da lembrança traumática e sua enunciação, que poderiam ser o começo de uma cura, mesmo de uma mudança de vida, não 
apenas não remontam facilmente, mas são duramente colocados de lado, rejeitados com toda a força pelo paciente preso às resistências do recalque, diz Freud, citado por Ricoeur $(2007$, p.84). De fato, essa lembrança e essa narração renovariam o sofrimento e destruiriam o equilíbrio precário, duramente conquistado, mesmo à custa da doença, pelo analisando. Ele indica claramente a presença do evento passado, mas o faz de maneira indireta: "O paciente não reproduz [o fato esquecido] em forma de lembrança, mas em forma de ação: ele o repete sem, obviamente saber que o repete" (Ricoeur, 2007, p.84). E essa repetição pode até levar a uma passagem ao ato, uma espécie de mímica distorcida do trauma inicial. Para que a "cura" ocorra, portanto, é necessária uma longa paciência do analista que não deve forçar um "resultado", mas dar tempo ao paciente para cessar as queixas e acusações e, escreve Freud, "não mais considerar sua doença como algo desprezível, mas olhá-la como um adversário digno de estima, como uma parte de si mesmo cuja presença é muito motivada e na qual convirá colher dados preciosos para sua vida ulterior" ${ }^{29}$ É esse trabalho difícil que Freud chama Durcharbeitung, trabalho que, por assim dizer, atravessa $(d u r c h)$ as várias camadas de recalque, resistência, vergonha e dor: "Trabalho é a palavra repetida várias vezes, e simetricamente oposta à compulsão: trabalho de rememoração contra compulsão por repetição", explicita Ricoeur. ${ }^{30}$ Observemos que a palavra "compulsão" traduz o termo alemão Zwang, substantivo derivado do verbo zwingen, restringir, forçar, encurralar, evocando uma violência que escraviza, enquanto o trabalho da lembrança (Erinnerung) visa a libertação da escravidão. Da mesma forma, o trabalho de luto (Tranerarbeit), que Freud opõe à melancolia no segundo texto citado por Ricoeur nesse capítulo, ${ }^{31}$ permite ao sujeito que perdeu uma pessoa amada (mas que também podia ter devoção por uma entidade abstrata como a pátria, o partido, a revolução) de não mergulhar em amargura e imobilidade, mas libere sua libido para novos objetos e novos projetos. O luto e a rememoração são, portanto, forças vitais - mas exigem tempo, paciência e persistência.

Já no ensaio de 1965 sobre Freud, Ricoeur (1965) havia mostrado o quanto a "tendência a repetir [...] O material recalcado, em vez de evocá-lo como uma lembrança" (ibidem, p.282), é mortífero. A compulsão (Zwang) à repetição introduz a pulsão de morte (ibidem p.290) porque encerra o sujeito em sua história e em sua dolorosa solidão, da qual ele não quer sair por medo da ameaça fulgurante do reconhecimento do evento traumático - do qual, no entanto, deseja se livrar quando empreende um processo analítico no qual sua fala pode se alimentar da escuta de um outro sujeito. É dizer o quanto a lembrança pode ser um aliado essencial da vida quando ela transforma o que ficava soterrado no silêncio em uma produção simbólica compartilhada com outros humanos. Mas isso quer dizer também que esse trabalho do lembrar só se torna possível quando ancora-se em um desejo de cura, no desejo de "mudar de vida", como dizemos, e não nesta inércia (Trägheit) que a vida orgânica também persegue em seu caminho para a morte, como Ricoeur ressalta, lendo Além do princípio do prazer (ibidem, p.285). 
Mas o que dizer do uso desse modelo freudiano para pensar melhor na dinâmica de uma memória coletiva? Se Ricoeur sabe muito bem que a transferência de um modelo vinculado à dinâmica da subjetividade singular não se aplica necessariamente à da chamada memória coletiva (foi também o problema de Freud em vários de seus escritos sobre sociedade ou religião) (Ricoeur, 2007, p.85), ele se permite, no entanto, adotar o paradigma da "rememoração, repetição, perlaboração" na última parte do livro dedicada à "condição histórica" quando se trata de analisar as formas sociais de esquecimento e impedimentos da memória, "a meio caminho entre transtornos atinentes a uma psicopatologia da vida cotidiana e transtornos atribuíveis a uma sociologia da ideologia" (Ricoeur, 2007, p.456). Citando o trabalho de Henry Rousso sobre o regime de Vichy e as hesitações que regulavam suas diferentes elaborações, Ricoeur retoma seu conceito de "obsessão pelo passado" e o acolhe como "parente [do conceito] de repetição [...], precisamente como oposto ao de perlaboração, de trabalho, de memória” (Ricoeur, 2007, p.456).

Podemos observar que Theodor W. Adorno (1998, p.555-72), retornando à Alemanha após a Segundo Guerra Mundial e a revelação da Shoah, também retomou esse texto de Freud e essa ideia de trabalho da memória, quando ele escreve, em 1959, o pequeno texto "O que significa: elaboração do passado?" tentando explicar essa noção na ordem do dia da República Federal Alemã, sem resvalar apenas na litania das acusações e da culpabilidade. Em outro contexto, as pesquisas sociológicas sobre a violência na América Latina, em particular sobre a persistência da tortura, mostram que, de fato, nos países que atravessaram uma ditadura e restabeleceram uma democracia, unicamente a denúncia e a elaboração de traumas coletivos, torturas, mortes, desaparecimentos, tornam possível interromper sua repetição, mesmo seu aumento perverso, em especial em relação às populações pobres e marginalizadas. ${ }^{32}$

Se a exigência freudiana do trabalho de perlaboração e, também, do trabalho de luto, para chegar a uma memória que faça justiça aos sofrimentos do passado e libere as forças de vida do presente pode, portanto, aplicar-se corretamente às tentativas coletivas de alcançar uma "política da justa memória" que Ricoeur convida desde a primeira página de seu livro, persiste, no entanto, uma dúvida que me permito expressar como conclusão. Seguindo Freud, Ricoeur (2007, p.84) insiste que o paciente pare de repetir e reclamar e ouse, como já citamos, "encontrar coragem para fixar sua atenção em suas manifestações mórbidas [...], mas olhar para ela [sua doença] como um adversário digno de estima, como uma parte de si cuja presença está bem motivado e na qual convirá colher dados preciosos para sua vida ulterior". Essa coragem é essencial, assim como a presença do analista que conforta, pela sua escuta, o caminho do paciente - não esqueçamos que Freud escreveu estas páginas no contexto mais amplo da "técnica" da cura. No entanto, nem a vontade do analisando nem a figura do analista têm seu equivalente nas atribuições da memória coletiva. E atualmente, neste ano de 2019, é como se uma onda de repetições sinistras se abatessem 
sobre muitas de nossas democracias cansadas. Certamente, a vontade e a coragem de se lhe opor, de ousar confrontar o não dito do passado para trazê-lo à memória e à fala, a fim de poder inventar uma outra ordem da vida em comum, essa coragem e essa vontade não faltam. Mas não há garantia de que elas possam prevalecer.

\section{Notas}

1 Lembremos que o primeiro volume dos ensaios de hermenêutica tinha um título diferente: O conflito das interpretações (Ricoeur, 1978).

2 Pierre Nora (1997) fala de "bulimia comemorativa" no último texto, "L'ère des commémorations," nesta imponente série organizada em três volumes (Les lieux de mémoive 3).

3 Como Ricoeur (2010) o diz em vários momentos, ver o índex temático ao final de $A$ memória, a história, o esquecimento.

4 "On sait l'harassante fuite en arrière de la pensée en quête de la première vérité, et plus radicalement encore à la recherche d'un point de départ qui pourrait bien ne pas être une première vérité; l'illusion n'est pas de chercher le point de départ, mais de le chercher sans présupposition; il n'y a pas de philosophie sans présupposition; une méditation sur les symboles part du langage qui a déjà eu lieu, et où tout a déjà été dit en quelque façon; elle veut être la pensée avec ses présuppositions. Pour elle, la première tâche n'est pas de commencer, mais, du milieu de la parole, de se ressouvenir; de se ressouvenir en vue de commencer" ["Sabemos da esgotante fuga do pensamento em busca da primeira verdade, e ainda mais radicalmente em busca de um ponto de partida que pode não ser uma primeira verdade; a ilusão não é buscar o ponto de partida, mas de buscá-lo sem pressupostos; não há filosofia sem pressuposto; uma meditação sobre os símbolos parte da linguagem que já ocorreu, e onde tudo já foi dito de alguma maneira; ela quer ser o pensamento com seus pressupostos. Para ela, a primeira tarefa não é começar, mas, do meio da palavra se relembrar; de se relembrar para começar" (tradução nossa)].

5 Nora (1997, p.23): “A extração do que ainda restou de vivido no calor da tradição, no silêncio dos costumes, na repetição do ancestral sob a pressão de um sentimento histórico de fundo" [...] "Falamos tanto sobre memória porque não há mais dela" (tradução nossa).

6 Nora (1997, p.26 e 25): “se desenvolveu como exercício regulado da memória e seu aprofundamento espontâneo" (tradução nossa).

7 Nora (1997, p.26): “se propõe a rastrear nela o que não é ela, descobrindo-se vítima da memória e fazendo um esforço para livrar-se" (tradução nossa).

8 Nora (1997, p.28): “a história se tornou uma ciência social”, “a memória [é] um fenômeno puramente privado” (tradução nossa).

9 Nora (1997, p.29): “mundo onde tínhamos antepassados para um mundo da relação contingente com o que nos fez" (tradução nossa).

10 Nora (1997, p.30): "Sem dúvida, é impossível prescindir da palavra [da palavra "memória”]. Aceitemo-lo, mas com uma consciência clara da diferença entre a memória verdadeira, hoje refugiada no gesto e no hábito, nas profissões onde se transmitem os saberes do silêncio, nos saberes do corpo, as memórias de impregnação e os saberes re- 
flexos e a memória transformada por sua passagem na história, que é quase seu contrário: voluntária e deliberada, vivida como um dever e não mais espontânea; psicológica, individual e subjetiva, e não mais social, coletiva, abrangente" (tradução nossa).

11 Nora (1997), último artigo: "L’ère des commémorations". "É a própria dinâmica da comemoração que foi revertida, o modelo memorial levou à vitória sobre o modelo histórico e, com ele, um uso completamente outro do passado, imprevisível, caprichoso. Um passado que perdeu seu caráter orgânico, peremptório e necessário. O que importa não é o que ele nos impõe, mas o que colocamos nele. De onde a confusão da mensagem, seja o que for. É o presente que cria seus instrumentos comemorativos, que corre atrás das datas e das figuras a serem comemoradas, que as ignora ou as multiplica, que se dá figuras arbitrárias dentro do programa imposto (como Valmy anexado a 1789) ou que tolera a data (por exemplo, 1994 para o caso Dreyfus, a condenação, não a reabilitação), mas para transformar seu significado. A história propõe, mas o presente dispõe, e o que acontece é em regra, diferente do que queríamos" (Nora, 1984, p.4696, tradução nossa).

12 Nora (1997, p.4697): "refabricação do passado" (tradução nossa).

13 Nora (1997, p.4704): "tal como foi constituída em professora da nação” (tradução nossa).

14 Nora (1997, p.4704): “com os meios disponíveis, dos mais selvagens aos mais científicos” (tradução nossa).

15 Nora (1997, p.4705): “do histórico para o rememorativo e do rememorativo para o comemorativo” (tradução nossa).

16 Nora (1997, p.4704): “uma memória verificada" (tradução nossa).

17 Citado pela primeira vez na página 34 de $A$ memória, a história, o esquecimento, esta frase do De memoria et reminiscentia de Aristoteles “acompanha”, diz Ricoeur (2007), "todo o meu percurso".

18 Ver Paul Ricoeur (1998), La marque du passé, Revue de Métaphysique et Morale, 1.

19 Evangelho de Lucas, 22,19.

\section{Livro X das Confissões}

21 Um termo de Bergson que Ricoeur retoma em uma entrevista, Revue Lire, octobre $2000,47$.

22 Ver Ricoeur, A memória, a história, o esquecimento, todo o capítulo III, em particular o paragrafo 3, "O esquecimento comandado: a anistia", da parte consagrada ao esquecimento, p.423 ss.

23 Uma confusão que a maioria dos regimes autoritários - mesmo que tenham uma aparência democrática, como por exemplo o Brasil - mantém proibindo tanto a denúncia de crimes passados como sua punição.

24 Por uma reflexão crítica sobre a inadequação da palavra ocidental "reconciliação" (Hegel, Versöhnung) para traduzir o termo ubuntu, leremos o artigo de Jacques Derrida “Versöbnung, ubuntu, pardon: quel genve?" no livro coletivo Vérité réconciliation réparation, editado por Cassin et al. (2004).

25 Paul Ricoeur, “Avant la justice non violente, la justice violente”, na coleção coletiva Vérité, réconciliation, réparation, 170: "Portanto, a relação entre a anistia e a confissão se torna essencial. Ela é individual e condicional, diferentemente das anistias gerais conce- 
didas na América Latina sob a pressão dos militares. Pela confissão, ela está ligada à fala e ao seu justo pacto com a verdade e não ao silêncio de não-dizer, como na justiça violenta, onde se desfaz a fronteira entre anistia e amnésia comandada" (tradução nossa).

26 Este é, entre outros, o caso da famosa lei de anistia promovida pelos militares brasileiros em 1979, cinco anos antes do fim da ditadura militar, lei que admitia o retorno ao Brasil de muitos exilados, mas que também tornou impossível denunciar os torturadores e puni-los.

27 A conferência “Sanction, réhabilitation, pardon", de onde tiro esta citação, foi pronunciada por Ricoeur em 30 abril de 1994: “À proibição de qualquer ação legal, portanto, à proibição de qualquer processo judicial criminoso, é adicionada a proibição de evocar os próprios fatos sob sua qualificação criminal. Portanto, se trata de uma verdadeira amnésia institucional que convida a agir como se o evento não houvesse ocorrido. [...] O preço a pagar é alto. Todos os males do esquecimento são contidos nesta pretensão incrível de apagar os rastros da discórdia pública. É neste sentido que a anistia é um oposto do perdão, o qual [...] requer a memória” (tradução nossa).

28 Sigmund Freud, “Erinnern, Wiederholen, Durcharbeiten”, Studienausgabe (Fischer Verlag, 1975, v.X, p.206-15). Ricoeur cita a tradução francesa de Antoine Berman (1970).

29 Citado por Ricoeur (2007, p.84).

30 Citado por Ricoeur $(2007$, p.85).

31 A saber Sigmund Freud, "Trauer und Melancholie," Studienausgabe, v.3 (1917). Ricoeur cita a tradução de Laplanche e Pontalis no volume Métapsychologie (Ricoeur, 1968).

32 Ver entre outros o artigo da jurista Flávia Piovesan na coleção O que resta da ditadura (Teles; Safatle, 2010).

\section{Referências}

ABEL, O.; POREE, J. Le vocabulaire de Paul Ricoeur. Paris: Ellipses, 2007.

ADORNO, T. W. Was bedeutet: Aufarbeitung der Vegangenheit? In: Eingriffe, Gesammelte Schriften. Wissenschaftlieche Buchgesellschaft, 1998, v.10-2, p.555-72.

BENJAMIN, W. Passagens. Trad. Irene Aron. Belo Horizonte: Editora UFMG, 2009.

BERMAN, A. La technique psychanalytique. Paris: Presses Universitaires de France, 1970.

CASSIN, B.; CAYLA, O.; SALAZAR, P.-J. Le genre humaine. Paris: Seuil, novembro de 2004.

DOSSE, F. Lieux, travail, devoir de mémoire chez Paul Ricoeur. In: Cabier de l'Herne. Consagrado à Ricoeur. Paris : Éditions de l'Herne, 2004. p.256-70.

FREUD, S. Erinnern, Wiederholen, Durcharbeiten. Studienausgabe. Fischer Verlag, 1975, v.X, 206-15.

. Trauer und Melancholie. Studienausgabe, v.3, 1917.

KOSELLECK, R. Vergangene Zukunft. Zur Semantik geschichtlicher Zeiten.Francfurt: Suhrkamp, 1979. 
NORA, P. L'ère des commémorations. In: Les lieux de mémoire. v.3, Les France.

Paris : Éditions Quarto, Gallimard, 1997.

RICOEUR, P. Finitude et culpabilité. La symbolique du mal. Paris: Aubier, 1960

. De l'interprétation. Essai sur Freud. Paris: Seuil, 1965.

. Métapsychologie. Paris: Gallimard, 1968.

1978.

. O conflito das interpretações. In: Ensaios de hermenêutica. São Paulo: Imago,

. Do texto à acção: ensaios de hermenêutica II. Porto: Rés, 1986.

. Le juste. Paris : Éditions Esprit, 1995.

. La marque du passé. Revue de Métaphysique et Morale, 1. 1998.

. A memória, a história, o esquecimento. Trad. Alain François. Campinas: Editora da Unicamp, 2007.

- O justo 1. Trad. Ivone C. Benedetti. São Paulo: Martins Fontes, 2008a.

. O Justo 2. Trad. Ivone C. Benedetti, São Paulo: Martins Fontes, 2008 b.

. Tempo e narrativa. Trad. Claudia Berliner e Márcia Valéria Martinez de Aguiar.

São Paulo: Editora WMF Martins Fontes, 2010.

. O si-mesmo como outro. Trad. Ivone C. Benedetti. São Paulo: Editora WMF Martins Fontes, 2014.

TELES, E.; SAFATLE, V. (Org.) O que resta da ditadura. São Paulo: Boitempo, 2010.

RESUMO - Este artigo tem como pressuposto que a retomada do tema da memória e do esquecimento, em A memória, a história, o esquecimento, parte de uma pesquisa da "justa memória" em um cenário político francês que sofre de "bulimia comemorativa", como denuncia Pierre Nora em Les lieux de mémoire. É apresentado o confronto entre uma concepção da memória imbuída de emoções subjetivas, em oposição ao rigor científico da história (Nora), e uma concepção da memória viva como condição transcendental de nossa relação com o passado (Ricoeur). Esse confronto se abre sobre a insistência do aspecto ético da política memorial e das práticas coletivas de esquecimento e de amnésia. Segundo Ricoeur, as hipóteses de Freud sobre a elaboração do trauma e sobre o trabalho do luto podem servir como paradigma privilegiado a esse empreendimento que visa uma narrativa histórica justa.

PALAVRAS-CHAVE: Memória, História, Rememoração, Representância, Justiça.

ABSTRACT - This article assumes that Ricoeur's approach to memory and forgetting in Memory, History, Forgetting stems from his reflections on "just memory" in a French political landscape that suffers from "commemorative bulimia," as Pierre Nora put it in Les lieux de mémoire (Realms of Memory). The article contrasts a concept of memory imbued with subjective emotions, in opposition to the scientific rigor of history (Nora), and a concept of living memory as the transcendental condition for our relationship 
with the past (Ricoeur). This confrontation underscores the ethical dimension of the politics of memory and of the collective practices of forgetting and amnesia. According to Ricoeur, Freud's hypotheses concerning trauma and mourning may serve as a paradigm for a task that aims at a just historical narrative.

KEYWORDS: Memory, History, Remembrance, Representance, Justice.

Jeanne Marie Gagnebin é professora de Filosofia na Pontifícia Universidade Católica de São Paulo (PUC-SP) e no Instituto de Estudos da Linguagem da Universidade Estadual de Campinas. Atualmente colaboradora do Departamento de Filosofia do Instituto de Filosofia e Ciências Humanas da Unicamp. @ - jmgagnebin@gmail.com / https://orcid.org/0000-0003-3979-2343

Tradução de Cleiton Neri de Santana. O original em francês - "Les empêchements de la mémoire", publicado em Études Ricoeuriennes / Ricoeur Studies, v.10, n.1, p.42-57, 2019 - encontra-se à disposição do leitor no Instituto de Estudos Avançados da USP para eventual consulta.

Recebido em 4.10.2019 e aceito em 28.1.2020.

I Faculdade de Filosofia, Comunicação, Letras e Artes, Pontifícia Universidade Católica de São Paulo, São Paulo, Brasil. 
